\title{
State of heat shock factor 1 expression as a putative diagnostic marker for oral squamous cell carcinoma
}

\author{
JUNYA ISHIWATA $^{1 *}$, ATSUSHI KASAMATSU $^{1,2^{*}}$, KENTARO SAKUMA $^{1}$, MANABU IYODA $^{1}$, \\ MASANOBU YAMATOJI ${ }^{1}$, KATSUYA USUKURA ${ }^{1}$, SHUNSAKU ISHIGE $^{1}$, TOSHIHIRO SHIMIZU ${ }^{1}$, \\ YUKIO YAMANO $^{1}$, KATSUNORI OGAWARA ${ }^{2}$, MASASHI SHIIBA ${ }^{2}$, \\ HIDEKI TANZAWA $^{1,2}$ and KATSUHIRO UZAWA ${ }^{1,2}$
}

${ }^{1}$ Department of Clinical Molecular Biology, Graduate School of Medicine, Chiba University; ${ }^{2}$ Division of Dentistry and Oral-Maxillofacial Surgery, Chiba University Hospital, 1-8-1 Inohana, Chuo-ku, Chiba 260-8670, Japan

Received June 29, 2011; Accepted August 5, 2011

DOI: 10.3892/ijo.2011.1178

\begin{abstract}
Heat shock factor 1 (HSF1) is responsible for expression of a large class of heat shock proteins that have been implicated in the malignant phenotype of human cancers. Little is known about the effect of a high level of HSF1 on the behavior of oral squamous cell carcinoma (OSCC). In this study, we assessed the value of HSF1 for predicting clinical outcomes in OSCC. Quantitative reverse transcriptase-polymerase chain reaction and Western blotting showed that the expressions of HSF1 mRNA and protein in OSCC-derived cell lines (HSC-2, HSC-3, HSC-4, Sa3, Ca9-22, KON and Ho-1-u-1) were elevated compared with those in human normal oral keratinocytes $(\mathrm{P}<0.05)$. Similar to in vitro data, HSF1 mRNA expression in primary OSCCs $(n=50)$ was significantly greater than in normal counterparts $(\mathrm{P}<0.05)$. Since HSF1 was observed in the nucleus and cytoplasm by immunohistochemistry, we investigated the correlation between the HSF1 expression status at each subcellular location and the clinical behavior of OSCCs. Among the clinical classifications, higher nuclear HSF1 expression was closely related to tumor size and histopathologic types $(\mathrm{P}<0.05)$. These results showed for the first time that nuclear HSF1 expression may contribute to cancer progression and that HSF1 might be a
\end{abstract}

Correspondence to: Dr Atsushi Kasamatsu or Dr Katsuhiro Uzawa, Department of Clinical Molecular Biology, Graduate School of Medicine, Chiba University, 1-8-1 Inohana, Chuo-ku, Chiba 260-8670, Japan

E-mail: kasamatsua@faculty.chiba-u.jp

E-mail:uzawak@faculty.chiba-u.jp

*Contributed equally

Key words: oral squamous cell carcinoma, heat shock factor 1, realtime quantitative reverse transcriptase PCR, Western blot analysis, immunohistochemistry potential diagnostic biomarker and a therapeutic target for OSCCs.

\section{Introduction}

Oral squamous cell carcinoma (OSCC) is a major cause of morbidity and mortality globally and accounts for 275,000 new cases and $>120,000$ deaths annually (1). Many risk factors have been identified, including tobacco and alcohol use (2-4). However, some patients develop OSCC without risk factors, suggesting that host susceptibility plays an important role. Molecular changes in the number of oncogenes and tumor suppressor genes associated with the development of OSCC could be important clues for preventing this disease $(3,5)$.

Heat shock factor 1 (HSF1) is an $82-\mathrm{kDa}$ transcription factor that is strongly activated in response to heat shock and other forms of environmental and chemical stresses. HSF1 is responsible for expression of a large class of heat shock proteins (HSPs), such as HSP27, HSP70 and HSP90, which protect cells from damage as a result of cellular insults, heat shock and oxidative stress (6,7). Many types of tumors express high concentrations of HSPs, which are correlated with increases in HSF1 levels (8-11). Elevated levels of HSP expression contribute directly to tumorigenesis through inhibition of programmed cellular death in tumors $(10,12)$, and thus protect cancer cells from chemotherapy and radiation therapy (9,13-17). HSF1 exists as a monomeric protein in the cytoplasm. On heat induction, monomeric HSF1 undergoes trimerization and nuclear localization (18-20). Although the trimer can bind to DNA, its transcription activity appears to be enhanced by stress-induced serine phosphorylation (21).

Microarray technology has been helpful for analyzing changes in thousands of genes and identifying relevant patterns. We previously reported the gene expression profiling of OSCC for identifying cancer-related genes associated with oral carcinogenesis (22). Among the genes, HSF1 was found to be significantly up-regulated in OSCC. In the current study, HSF1 was frequently overexpressed in OSCC-derived cell lines and primary OSCCs. Therefore, we suggested that HSF1 might be a diagnostic biomarker and potential therapeutic target for OSCCs. 


\section{Materials and methods}

OSCC-derived cell lines and tissue specimens. HSC-2, HSC-3, HSC-4, Ca9-22, KON and Ho-1-u-1 cell lines, derived from human OSCCs, were purchased from the Human Science Research Resources Bank (Osaka, Japan). The Sa3 cell line was kindly provided by Dr S. Fujita at Wakayama Medical University (Wakayama, Japan). Primary cultured human normal oral keratinocytes (HNOKs) were obtained from three healthy donors $(23,24)$. All cells were grown in Dulbecco's modified Eagle's medium/F-12 HAM (SigmaAldrich Co., St. Louis, MO) supplemented with $10 \%$ fetal bovine serum (Sigma) and $50 \mathrm{U} / \mathrm{ml}$ penicillin and streptomycin (Sigma).

Tissue samples from 50 unrelated Japanese patients with primary OSCC who were treated at Chiba University Hospital were obtained during surgical resection. The resected tissues were divided into two parts; one was frozen immediately and stored at $-80^{\circ} \mathrm{C}$ until RNA isolation, and the second was fixed in $10 \%$ buffered formaldehyde solution for pathologic diagnosis and immunohistochemistry (IHC). The Department of Pathology, Chiba University Hospital conducted the histopathologic analysis of the tissues according to the World Health Organization criteria. Clinicopathologic staging was determined by the TNM classification of the International Union against Cancer. All patients had OSCC that was histologically confirmed, and tumor samples were checked to ensure that tumor tissue was present in $>90 \%$ of the specimen.

Preparation of cDNA. Total RNA was isolated using TRIzol reagent (Invitrogen, Carlsbad, CA) according to the manufacturer's instructions. cDNA was generated from $5 \mu \mathrm{g}$ of total RNA using Ready-To-Go You-Prime First-Strand Beads (GE Healthcare, Buckinghamshire, UK) and oligo(dT) primer (Sigma Genosys, Ishikari, Japan), according to the manufacturer's instructions.

$m R N A$ expression analysis. Real-time quantitative reverse transcriptase PCR (qRT-PCR) was performed to evaluate the expression levels of HSF1 genes in OSCC-derived cells and primary OSCCs. qRT-PCR was carried out with one method using a LightCycler FastStart DNA Master SYBR-Green 1 Kit (Roche Diagnostics GmbH, Mannheim, Germany). The following primers were used: HSF1, forward 5'-TGGCCATGA AGCATGAGAATGACA-3' and reverse 5'-AGCCACTG TCGTTCAGCATCA-3'. Amplified products were analyzed by $3 \%$ agarose gel electrophoresis to ascertain size and purity. The PCR reactions using the LightCycler apparatus were performed in a final volume of $20 \mu \mathrm{l}$ of a reaction mixture consisting of $2 \mu \mathrm{l}$ of FirstStart DNA Master SYBR-Green I mix, $3 \mathrm{mM} \mathrm{MgCl}_{2}$, and $1 \mu \mathrm{M}$ of the primers, according to the manufacturer's instructions. The reaction mixture was loaded into glass capillary tubes and subjected to an initial denaturation at $95^{\circ} \mathrm{C}$ for $10 \mathrm{~min}$, followed by 45 rounds of amplification at $95^{\circ} \mathrm{C}(10 \mathrm{sec})$ for denaturation, $62^{\circ} \mathrm{C}(10 \mathrm{sec})$ for annealing, and $72^{\circ} \mathrm{C}(10 \mathrm{sec})$ for extension, with a temperature slope of $20^{\circ} \mathrm{C} / \mathrm{sec}$. The transcript amounts for the target genes were estimated from the respective standard curves and normalized to the glyceraldehyde-3-phosphate dehydrogenase (GAPDH) (forward 5'-CATCTCTGCCCCCTCTGCTGA-3' and reverse
5'-GGATGACCTTGCCCACAGCCT-3') transcript amount determined in corresponding samples.

Protein extraction. The cells were washed twice with cold phosphate-buffered saline (PBS) and centrifuged briefly. The cell pellets were incubated at $4{ }^{\circ} \mathrm{C}$ for $30 \mathrm{~min}$ in a lysis buffer (7 $\mathrm{M}$ urea, $2 \mathrm{M}$ thiourea, $4 \% \mathrm{w} / \mathrm{v}$ CHAPS, and $10 \mathrm{mM}$ Tris $\mathrm{pH}$ 7.4) with proteinase inhibitor cocktail (Roche). The protein concentration was measured with the BCA protein assay kit (Thermo, Rockford, IL).

Western blot analysis. Protein extracts were electrophoresed on 4-12\% Bis-Tris gel, transferred to nitrocellulose membranes (Invitrogen), and blocked for $1 \mathrm{~h}$ at room temperature in Blocking One (Nacalai Tesque, Kyoto, Japan). The membranes were washed three times with $0.1 \%$ Tween-20 in Tris-buffered saline and incubated with $2 \mu \mathrm{g} / \mathrm{ml}$ affinity-purified rabbit anti-human HSF1 monoclonal antibody (Thermo) overnight at $4^{\circ} \mathrm{C}$. The membranes were washed again and incubated with a 1:10,000 of goat anti-rabbit $\operatorname{IgG}(\mathrm{H}+\mathrm{L})$ horseradish peroxidase conjugate (Promega, Madison, WI) as a secondary antibody for $2 \mathrm{~h}$ at room temperature. Finally, the membranes were detected using SuperSignal West Pico Chemiluminescent substrate (Thermo) and immunoblotting was visualized by exposing the membranes to ATTO Light-Capture II (ATTO, Tokyo, Japan). Signal intensities were quantitated using the CS Analyzer version 3.0 software (ATTO).

IHC. IHC of 4- $\mu \mathrm{m}$ sections of paraffin-embedded specimens was performed using rabbit anti-HSF1 monoclonal antibody (Thermo). Briefly, after deparaffinization and hydration, the endogenous peroxidase activity was quenched by $30-\mathrm{min}$ incubation in a mixture of $0.3 \%$ hydrogen peroxide solution in $100 \%$ methanol, after which the sections were blocked for $2 \mathrm{~h}$ at room temperature with $1.5 \%$ blocking serum (Santa Cruz Biotechnology, Santa Cruz, CA) in PBS before reaction with anti-HSF1 antibody (1:100 dilution) at $4^{\circ} \mathrm{C}$ in a moist chamber overnight. Upon incubation with the primary antibody, the specimens were washed three times in PBS and treated with Envision reagent (Dako, Carpinteria, CA) followed by color development in 3,3'-diaminobenzidine tetrahydrochloride (Dako). The slides then were lightly counterstained with hematoxylin, dehydrated with ethanol, cleaned with xylene, and mounted. Non-specific binding of an antibody to proteins other than the antigen sometimes occurred. To avoid nonspecific binding, an immunizing peptide blocking experiment was performed. As a negative control, triplicate sections were immunostained without exposure to primary antibodies, which confirmed the staining specificity. To quantify the state of HSF1 protein expression in subcellular fractionations (nucleus, nucleus plus cytoplasm and cytoplasm), we used IHC score systems described previously $(22,24-33)$. Briefly, the stained cells were determined in at least five random fields at $\mathrm{x} 400$ magnification in each section. The intensity of the HSF1 immunoreaction in the cell was scored as follows: 1+, weak; $2+$, moderate; and $3+$, intense. The cellular number and the staining intensity then were multiplied to produce an HSF1 IHC score. Cases exceeding the highest IHC score for normal tissue in each fractionation (nucleus, 89.0; nucleus plus cytoplams, 108.0; cytoplasm, 109.0) were defined as HSF1-positive. 
Two independent pathologists, both of whom were masked to the patients' clinical status, made these judgments.

Statistical analysis. The statistical significance of the HSF1 expression levels was evaluated using the Mann-Whitney $\mathrm{U}$ test. $\mathrm{P}<0.05$ was considered statistically significant. The data are expressed as the mean \pm standard error of the mean (SEM).

\section{Results}

Evaluation of HSF1 mRNA expression in OSCC-derived cell lines. To investigate mRNA expression of $H S F 1$, we performed qRT-PCR analysis using six OSCC-derived cell lines (HSC-2, HSC-3, HSC-4, Sa3, Ca9-22, KON and Ho-1-u-1) and HNOKs. mRNA expression levels were normalized to GAPDH. HSF 1 mRNA was significantly up-regulated in all OSCC cell lines compared with the HNOKs (Fig. 1, ${ }^{*} \mathrm{P}<0.05$ ).

Evaluation of $H S F 1$ protein expression in OSCC-derived cell lines. We performed Western blot analysis to investigate HSF1 protein expression status in the OSCC-derived cell lines and the HNOKs (Fig. 2). The molecular weight of the HSF1 was $82 \mathrm{kDa}$. A significant increase in HSF1 protein expression was observed in all OSCC cell lines compared with the HNOKs. Expression analysis indicated that both transcription and translation products of this molecule were highly expressed in OSCC-derived cell lines.

Evaluation of HSF1 mRNA expression in primary OSCCs. We measured the HSF 1 mRNA expression levels in primary OSCCs and paired normal oral tissues from 50 patients. Similar to the data from the OSCC-derived cell lines, qRT-PCR analysis showed that HSF1 mRNA expression was up-regulated in 37 (74\%) of 50 primary OSCCs compared with the matched normal oral tissues (Fig. 3, P<0.05). The relative mRNA expression levels in the primary OSCCs and normal oral tissues ranged from 0.004 to 8.29 (median, 0.121) and 0.002-2.15 (median, $0.054)$, respectively.

Evaluation of HSF1 protein expression in primary OSCCs. We then analyzed HSF1 protein expression by IHC. Representative IHC results for HSF1 protein in normal oral tissue and primary OSCCs are shown in Fig. 4A and B. A positive immunoreaction for HSF1 was detected in the nucleus and cytoplasm. Strong HSF1 immunoreactions were detected in OSCCs, whereas normal oral tissues showed negative immunostaining. The HSF1 IHC nuclei scores in OSCCs and normal oral tissues ranged from 12.0 to 258.0 (median, 102.0) and 2.0-89.0 (median, 27.0), respectively. The nucleus plus cytoplasm scores in the OSCCs and normal oral tissues ranged from 53.0 to 206.0 (median, 111.0) and 42.0-108.0 (median, 69.5), respectively. The cytoplasm scores in the OSCCs and normal oral tissues ranged from 56.0 to 208.0 (median, 104.25) and 43.0-109.0 (median, 67.25), respectively. The HSF1 IHC scores in each fractionation of primary OSCCs were significantly greater than those in normal tissues (Fig. $4 \mathrm{C}$, nucleus, $\mathrm{P}=0.018$; Fig. 4D, nucleus plus cytoplasm, $\mathrm{P}=0.027$; Fig. 4E, cytoplasm, $\mathrm{P}=0.048)$. The correlations between the clinicopathologic characteristics of the patients with OSCC and the status of

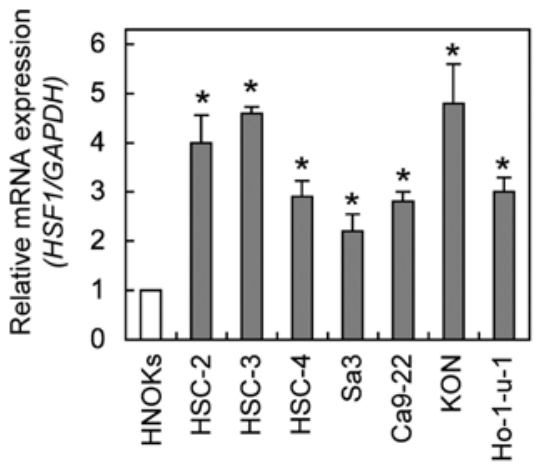

Figure 1. Quantification of HSF1 mRNA levels in OSCC-derived cell lines by qRT-PCR analysis. To determine mRNA expression status of $H S F 1$, we performed qRT-PCR analysis using seven OSCC-derived cell lines (HSC-2 HSC-3, HSC-4, Sa3, Ca9-22, KON and Ho-1-u-1) and HNOKs. Significant up-regulation of HSF1 mRNA is seen in the seven OSCC-derived cell lines compared with that in the HNOKs. Data are expressed as the means \pm SEM of values from three assays ( $(\mathrm{P}<0.05$; Mann-Whitney $\mathrm{U}$ test).

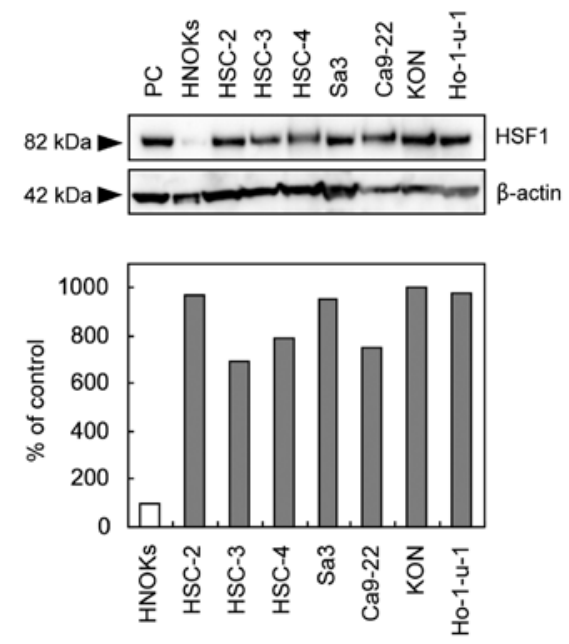

Figure 2. Western blot analysis of HSF1 protein in the OSCC-derived cell lines and HNOKs. To investigate protein expression status of HSF1, we performed Western blot analysis using seven OSCC-derived cell lines (HSC-2, HSC-3, HSC-4, Sa3, Ca9-22, KON and Ho-1-u-1) and HNOKs. HSF1 protein expression is up-regulated in OSCC-derived cell lines compared with HNOKs. Densitometric HSF1 protein data are normalized to $\beta$-actin protein levels. The values are expressed as a percentage of the HNOKs.

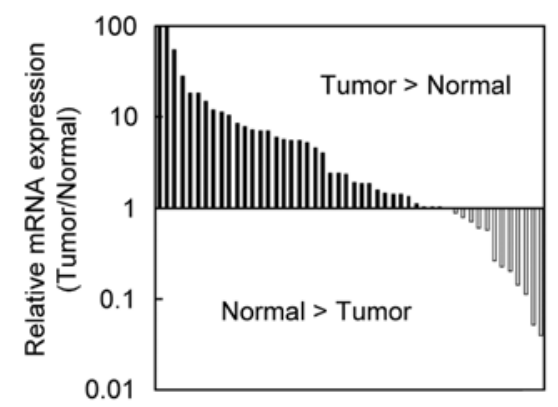

Figure 3. Comparison of HSF1 mRNA expression levels between primary OSCCs and matched normal oral tissues. To investigate the HSF 1 mRNA expression levels in primary OSCCs and paired normal oral tissues from 50 patients, we performed qRT-PCR analysis. HSF1 mRNA expression is up-regulated in $37(74 \%)$ of 50 primary OSCCs compared with the matched normal oral tissues $(\mathrm{P}<0.05$; Mann-Whitney $\mathrm{U}$ test $)$. 

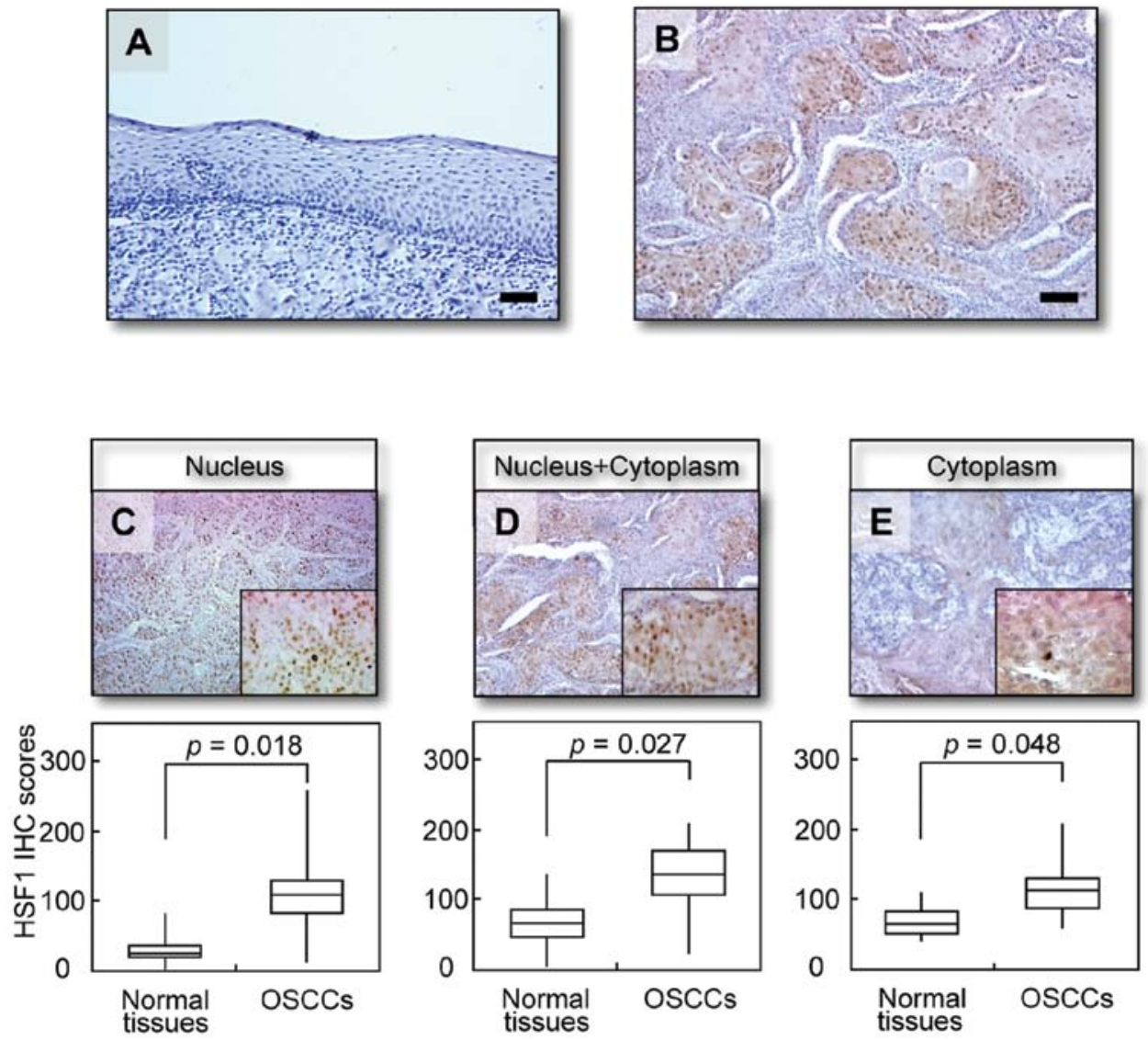

Figure 4. Evaluation of HSF1 protein expression in primary OSCCs. (A and B) Representative IHC results of HSF1 in normal oral tissue and primary OSCCs. (A) Normal oral tissue has no HSF1 protein expression. Original magnification, x100 and x400. Scale bars, $50 \mu \mathrm{m}$. (B) HSF1-positive cases of OSCC. Positive immunoreaction for HSF1 is detected in the nucleus and cytoplasm. Original magnification, $\mathrm{x} 100$ and x400. Scale bars, $50 \mu \mathrm{m}$. (C-E) State of HSF1 protein expression in subcellular fractionations of normal oral tissues and primary OSCCs by IHC score systems. The HSF1 IHC scores are calculated as follows: IHC score $=1 \mathrm{X}$ (number of weakly stained cells in the field) $+2 X$ (number of moderately stained cells in the field) $+3 X$ (number of intensely stained cells in the field). The HSF1 protein expression level in OSCCs is significantly $(\mathrm{P}<0.05)$ higher than in normal oral tissues (Mann-Whitney U test). (C) The HSF1 IHC scores of the nuclei in OSCCs and normal oral tissues ranged from 12.0 to 258.0 (median, 102.0) and 2.0-89.0 (median, 27.0), respectively. (D) The IHC scores of the nucleus plus cytoplasm in OSCCs and normal oral tissues ranged from 53.0 to 206.0 (median, 111.0) and 42.0-108.0 (median, 69.5), respectively. (E) The IHC scores of cytoplasm in OSCCs and normal oral tissues ranged from 56.0 to 208.0 (median, 104.25) and 43.0-109.0 (median, 67.25), respectively.

HSF1 protein expression in the nucleus using the IHC scoring system are shown in Table I. Among the clinical classifications, HSF1-positive OSCCs were correlated with tumor size $(\mathrm{P}=0.039)$ and histopathologic types of OSCC $(\mathrm{P}=0.004)$.

\section{Discussion}

Our previous microarray data (22) showed significant up-regulation of $H S F 1$ in OSCC-derived cell lines. The current data showed that HSF1 mRNA and protein were highly expressed in vitro and in vivo in OSCC. The 8q24 locus includes HSF1 as well as cancer-related genes, $M Y C$ proto-oncogene, $P V T 1$ and PTK2 $(34,35)$. The regional copy number of $8 \mathrm{q} 24$ increases in several cancer types, such as prostate, bladder and pancreas cancers (34-37). Therefore, genomic unbalance would be the reason for HSF1 overexpression in OSCC. The HSF1 protein expression levels in primary OSCCs were correlated with tumor size (Table I) $(\mathrm{P}<0.05)$, suggesting that HSF1 has an important role in OSCC development and progression. However, little is known about the relationship between HSF1 expression status and clinical classifications of OSCCs.
In the current study, significant up-regulation of $H S F I$ mRNA was observed in seven OSCC-derived cell lines and primary OSCCs compared with the matched normal counterparts. These results were consistent with previous reports that aberrant expression of HSF1 and HSPs (HSP27, HSP70 and HSP90) has been observed in aggressively malignant human cancer tissues $(7-9,17,38,39)$. Inactivation of HSF1 confers complex phenotypes, indicating that HSF1 has essential functions for growth, development and acute response to stress (40). Furthermore, HSF1 knockdown showed up-regulation of p21 and led to arrest of cell cycle progression at the G1 phase in cancer cells (41). Thus, HSF1 plays a broader role not only in cellular signaling beyond its well-known roles in stress response but also in cellular growth.

HSF1 is converted from an inactive monomer to a DNA binding trimer upon sensing stress. Active HSF1 trimer localizes to the nucleus, binds DNA and acts as a transactivator (38). Nuclear HSF1 directly activates transcription of HSPs (8-11). High progression of prostate cancer showed strong immunoreactivity of nuclear HSF1 compared with lowprogression tumors (8). We speculated that nuclear HSF1 
Table I. Correlation between nuclear HSF1 expression and clinical classification in OSCCs.

\begin{tabular}{|c|c|c|c|c|}
\hline \multirow[b]{2}{*}{ Clinical classification } & \multirow[b]{2}{*}{ Total } & \multicolumn{2}{|c|}{$\begin{array}{l}\text { Results of immunostaining } \\
\mathrm{n}(\%)\end{array}$} & \multirow[b]{2}{*}{ P-value } \\
\hline & & HSF1(-) & HSF1(+) & \\
\hline \multicolumn{5}{|l|}{ Age at surgery (years) } \\
\hline$<60$ & 11 & $6 \quad(55)$ & $5(45)$ & 0.476 \\
\hline $60-70$ & 12 & $5 \quad(42)$ & $7(58)$ & \\
\hline$>70$ & 27 & $9 \quad(33)$ & $18(67)$ & \\
\hline \multicolumn{5}{|l|}{ Gender } \\
\hline Male & 31 & 13 (42) & $18(58)$ & 0.721 \\
\hline Female & 19 & $7 \quad(37)$ & $12(63)$ & \\
\hline \multicolumn{5}{|l|}{ T-primary tumor } \\
\hline $\mathrm{T} 1$ & 5 & $3(60)$ & $2(40)$ & $0.039^{\mathrm{a}}$ \\
\hline $\mathrm{T} 2$ & 20 & $12(60)$ & $8(40)$ & \\
\hline $\mathrm{T} 3$ & 9 & $2(22)$ & $7(78)$ & \\
\hline $\mathrm{T} 4$ & 16 & 3 (19) & $13(81)$ & \\
\hline $\mathrm{T} 1+\mathrm{T} 2$ & 25 & $15 \quad(60)$ & $10(40)$ & $0.015^{\mathrm{a}}$ \\
\hline $\mathrm{T} 3+\mathrm{T} 4$ & 25 & $5 \quad(20)$ & $20(80)$ & \\
\hline \multicolumn{5}{|l|}{$\mathrm{N}$-regional lymph node } \\
\hline $\mathrm{N}^{+}$ & 32 & $7 \quad(39)$ & $11(61)$ & 0.904 \\
\hline $\mathrm{N}^{-}$ & 18 & $13(41)$ & $19(59)$ & \\
\hline \multicolumn{5}{|l|}{ Stage } \\
\hline $\mathrm{I}$ & 4 & $2(50)$ & $2(50)$ & 0.97 \\
\hline II & 16 & 7 (44) & $9(56)$ & \\
\hline III & 5 & $1 \quad(20)$ & $4(80)$ & \\
\hline IV & 25 & $10 \quad(40)$ & $15(60)$ & \\
\hline \multicolumn{5}{|l|}{ Histopathological type } \\
\hline Well differentiated & 29 & $8 \quad(28)$ & $21(72)$ & $0.004^{\mathrm{a}}$ \\
\hline Moderately differentiated & 15 & $6 \quad(40)$ & $9(60)$ & \\
\hline Poorly differentiated & 6 & $6(100)$ & $0 \quad(0)$ & \\
\hline \multicolumn{5}{|l|}{ Tumor site } \\
\hline Gingiva & 15 & $5 \quad(33)$ & $10(67)$ & 0.593 \\
\hline Tongue & 27 & 10 & $17(63)$ & \\
\hline Buccal mucosa & 5 & $3(60)$ & $2(40)$ & \\
\hline Oral floor & 2 & $1 \quad(50)$ & $1(50)$ & \\
\hline Soft palate & 1 & $1(100)$ & $0 \quad(0)$ & \\
\hline
\end{tabular}

${ }^{\mathrm{a}} \mathrm{P}<0.05$.

was correlated with clinical behavior of OSCCs rather than cytoplasmic HSF1. Consistent with our hypothesis, our data suggested that nuclear HSF1 has great potential to be a diagnostic and progression biomarker compared with cytoplasmic HSF1.

Because the prognosis of well-differentiated cancers is generally better than that of poorly differentiated cancers (42), many investigators have continued in their efforts to identify suitable biomarkers for the degree of differentiation of cancer. Interestingly, our data also showed that nuclear HSF1 was immunoreacted weakly in all poorly differentiated OSCC samples, whereas HSF1 protein expression in primary OSCCs was significantly higher than in normal oral tissues. These factors suggested that HSF1 might be a differentiation biomarker for
OSCC. However, the current study included only six cases of poorly differentiated OSCC. Therefore, further studies with more clinical samples are needed to address in greater detail the status of HSF1 in oral progression and prognosis.

In conclusion, our results indicated that HSF1 is overexpressed frequently in OSCC. These data suggested that HSF1 plays an important role in OSCC progression. HSF1 expression is likely to be a biomarker of progression and a potential therapeutic target for development of anticancer drugs in primary OSCCs.

\section{Acknowledgments}

We thank Lynda C. Charters for editing this manuscript. 


\section{References}

1. Sudbo J and Reith A: The evolution of predictive oncology and molecular-based therapy for oral cancer prevention. Int J Cancer 115: 339-345, 2005.

2. Mashberg A, Boffetta P, Winkelman R and Garfinkel L: Tobacco smoking, alcohol drinking, and cancer of the oral cavity and oropharynx among U.S. veterans. Cancer 72: 1369-1375, 1993.

3. Fearon ER and Vogelstein B: A genetic model for colorectal tumorigenesis. Cell 61: 759-767, 1990.

4. Macfarlane GJ, Zheng T, Marshall JR, et al: Alcohol, tobacco, diet and the risk of oral cancer: A pooled analysis of three casecontrol studies. Eur J Cancer B Oral Oncol 31: 181-187, 1995

5. Marshall CJ: Tumor suppressor genes. Cell 64: 313-326, 1991.

6. Sorger PK: Heat shock factor and the heat shock response. Cell 65: 363-366, 1991.

7. Morano KA and Thiele DJ: Heat shock factor function and regulation in response to cellular stress, growth and differentiation signals. Gene Expr 7: 271-282, 1999.

8. Hoang AT, Huang J, Rudra-Ganguly N, et al: A novel association between the human heat shock transcription factor 1 (HSF1) and prostate adenocarcinoma. Am J Pathol 156: 857-864, 2000.

9. Tang D, Khaleque MA, Jones EL, et al: Expression of heat shock proteins and heat shock protein messenger ribonucleic acid in human prostate carcinoma in vitro and in tumors in vivo. Cell Stress Chaperones 10: 46-58, 2005.

10. Ciocca DR and Calderwood SK: Heat shock proteins in cancer: diagnostic, prognostic, predictive, and treatment implications. Cell Stress Chaperones 10: 86-103, 2005.

11. Khaleque MA, Bharti A, Sawyer D, et al: Induction of heat shock proteins by heregulin beta1 leads to protection from apoptosis and anchorage-independent growth. Oncogene 24: 6564-6573, 2005.

12. Jones EL, Zhao MJ, Stevenson MA and Calderwood SK: The 70 kilodalton heat shock protein is an inhibitor of apoptosis in cancer. Int J Hyperthermia 20: 835-849, 2004.

13. Ciocca DR and Vargas-Roig LM: Hsp27 as a prognostic and predictive factor in cancer. Prog Mol Subcell Biol 28: 205-218, 2002.

14. Ricaniadis N, Kataki A, Agnantis N, Androulakis G and Karakousis CP: Long-term prognostic significance of HSP-70, c-myc and HLA-DR expression in patients with malignant melanoma. Eur J Surg Oncol 27: 88-93, 2001.

15. Strik HM, Weller M, Frank B, et al: Heat shock protein expression in human gliomas. Anticancer Res 20: 4457-4462, 2000.

16. Mosser DD and Morimoto RI: Molecular chaperones and the stress of oncogenesis. Oncogene 23: 2907-2918, 2004.

17. Calderwood SK, Khaleque MA, Sawyer DB and Ciocca DR: Heat shock proteins in cancer: chaperones of tumorigenesis. Trends Biochem Sci 31: 164-172, 2006.

18. Newton EM, Knauf U, Green M and Kingston RE: The regulatory domain of human heat shock factor 1 is sufficient to sense heat stress. Mol Cell Biol 16: 839-846, 1996.

19. Wisniewski J, Orosz A, Allada R and Wu C: The C-terminal region of Drosophila heat shock factor (HSF) contains a constitutively functional domain. Nucleic Acids Res 24: 367-374, 1996.

20. Rabindran SK, Haroun RI, Clos J, Wisniewski J and Wu C: Regulation of heat shock factor trimer formation: role of a conserved leucine zipper. Science 259: 230-234, 1993.

21. Cotto JJ, Kline M and Morimoto RI: Activation of heat shock factor 1 DNA binding precedes stress-induced serine phosphorylation. Evidence for a multistep pathway of regulation. J Biol Chem 271: 3355-3358, 1996.

22. Yamano Y, Uzawa K, Shinozuka K, et al: Hyaluronan-mediated motility: A target in oral squamous cell carcinoma. Int J Oncol 32: 1001-1009, 2008.

23. Kasamatsu A, Uzawa K, Nakashima D, et al: Galectin-9 as a regulator of cellular adhesion in human oral squamous cell carcinoma cell lines. Int J Mol Med 16: 269-273, 2005.
24. Endo Y, Uzawa K, Mochida Y, et al: Sarcoendoplasmic reticulum $\mathrm{Ca}(2+)$ ATPase type 2 downregulated in human oral squamous cell carcinoma. Int J Cancer 110: 225-231, 2004.

25. Shimada K, Uzawa K, Kato M, et al: Aberrant expression of RAB1A in human tongue cancer. Br J Cancer 92: 1915-1921, 2005.

26. Saito K, Uzawa K, Endo Y, et al: Plasma membrane $\mathrm{Ca}^{2+}$ ATPase isoform 1 down-regulated in human oral cancer. Oncol Rep 15: 49-55, 2006.

27. Onda T, Uzawa K, Endo Y, et al: Ubiquitous mitochondrial creatine kinase downregulated in oral squamous cell carcinoma. Br J Cancer 94: 698-709, 2006.

28. Kouzu Y, Uzawa K, Koike H, et al: Overexpression of stathmin in oral squamous-cell carcinoma: Correlation with tumour progression and poor prognosis. Br J Cancer 94: 717-723, 2006.

29. Kato Y, Uzawa K, Yamamoto N, et al: Overexpression of Septin1: Possible contribution to the development of oral cancer. Int $\mathbf{J}$ Oncol 31: 1021-1028, 2007.

30. Nomura H, Uzawa K, Yamano Y, et al: Overexpression and altered subcellular localization of autophagy-related 16-like 1 in human oral squamous-cell carcinoma: Correlation with lymphovascular invasion and lymph-node metastasis. Hum Pathol 40: 83-91, 2009.

31. Sakuma T, Uzawa K, Onda T, et al: Aberrant expression of histone deacetylase 6 in oral squamous cell carcinoma. Int J Oncol 29: 117-124, 2006.

32. Tanaka C, Uzawa K, Shibahara T, et al: Expression of an inhibitor of apoptosis, survivin, in oral carcinogenesis. J Dent Res 82: 607-611, 2003.

33. Lombardi DP, Geradts J, Foley JF, Chiao C, Lamb PW and Barrett JC: Loss of KAIl expression in the progression of colorectal cancer. Cancer Res 59: 5724-5731, 1999.

34. You L, Chang D, Du HZ and Zhao YP: Genome-wide screen identifies PVT1 as a regulator of Gemcitabine sensitivity in human pancreatic cancer cells. Biochem Biophys Res Commun 407: 1-6, 2011.

35. Matsuda R, Enokida H, Chiyomaru T, et al: LY6K is a novel molecular target in bladder cancer on basis of integrate genomewide profiling. Br J Cancer 104: 376-386, 2010.

36. Mahlamäki EH, Bärlund M, Tanner M, et al: Frequent amplification of $8 \mathrm{q} 24,11 \mathrm{q}, 17 \mathrm{q}$, and $20 \mathrm{q}$-specific genes in pancreatic cancer. Genes Chromosomes Cancer 35: 353-358, 2002.

37. Ahmadiyeh N, Pomerantz MM, Grisanzio C, et al: 8q24 prostate, breast, and colon cancer risk loci show tissue-specific long-range interaction with MYC. Proc Natl Acad Sci USA 107: 9742-9746, 2010.

38. Morimoto RI, Jurivich DA, Kroeger PE, et al: Regulation of heat shock gene transcription by a family of heat shock factors. In: The Biology of Heat Shock Proteins and Molecular Chaperones. Morimoto RI, Tisieres A and Georgopoulos C (eds). Cold Spring Harbor Press, New York, pp417-455, 1994.

39. Cen H, Zheng S, Fang YM, Tang XP and Dong Q: Induction of HSF1 expression is associated with sporadic colorectal cancer. World J Gastroenterol 10: 3122-3126, 2004.

40. McMillan DR, Xiao X, Shao L, Graves K and Benjamin IJ: Targeted disruption of heat shock transcription factor 1 abolishes thermotolerance and protection against heat-inducible apoptosis. J Biol Chem 273: 7523-7528, 1998.

41. Meng L, Gabai VL and Sherman MY: Heat-shock transcription factor HSF1 has a critical role in human epidermal growth factor receptor-2-induced cellular transformation and tumorigenesis. Oncogene $29: 5204-5213,2010$.

42. Nishida T, Katayama S, Tsujimoto M, Nakamura J and Matsuda $\mathrm{H}$ : Clinicopathological significance of poorly differentiated thyroid carcinoma. Am J Surg Pathol 23: 205-211, 1999. 